\title{
Comparison of an increased waist circumference with a positive hydrogen breath test as a clinical predictor of lactose intolerance
}

\author{
Carlos A. Zapata-Castilleja, M.D. ${ }^{a}$, Fernando F. Montes-Tapia, M.D. ${ }^{a}$, \\ Consuelo Treviño-Garza, M.D. ${ }^{a}$, María C. Martínez-Cobos, M.D. ${ }^{a}$, \\ Jesús García-Cantú, M.D. ${ }^{a}$,Vincenzo Arenas-Fabbri, M.D. ${ }^{a}$, \\ Norma de la O-Escamilla, M.D. ${ }^{a}$ and Manuel de la O-Cavazos, M.D. ${ }^{a}$
}

\begin{abstract}
Introduction. Lactose intolerance is a common disease in pediatrics, and its wrong diagnosis will lead to morbidity. The primary objective of this study was to assess the usefulness of an increased waist circumference during the hydrogen breath test as a predictor of lactose intolerance. The secondary objective was to analyze the impact of body mass index, waist circumference measurement, and age on the abdominal distension of patients with lactose intolerance.
\end{abstract}

Population and methods. A total of 138 subjects aged 3 to 15 years were included. They underwent serial measurements of the waist circumference and hydrogen levels in the breath every 30 minutes over 3 hours during the hydrogen breath test.

Results. Out of the entire sample, 35 (25.4\%) patients had lactose intolerance. An increase of $0.85 \mathrm{~cm}$ in waist circumference compared to the baseline waist circumference results in a sensitivity of $88 \%$ and a specificity of $85 \%$ to predict lactose intolerance (odds ratio: 42.14, $95 \%$ confidence interval: $13.08-135.75, p \leq 0.001)$. The body mass index and waist circumference measurementdid notaffectabdominaldistension ( $p=$ not significant); however, age modified the time of distension.

Conclusions. A $0.85 \mathrm{~cm}$ increase in waist circumference compared to the baseline waist circumference during the hydrogen breath test is a useful parameter for the diagnosis of lactose intolerance in pediatrics. Variations in relation to body mass index and waist circumference did not affect the usefulness of an increased waist circumference, unlike age.

Key words: lactose intolerance, waist circumference, diagnosis, exhaled hydrogen breath, child.

http:/ /dx.doi.org/10.5546/aap.2017.eng.148

This study was

financially supported

by the Support

Program for Scientific and Technological Research of Universidad Autónoma de Nuevo León.

To cite: Zapata-Castilleja CA, Montes-Tapia FF, Treviño-Garza C, et al. Comparison of an increased waist circumference with a positive hydrogen breath test as a clinical predictor of lactose intolerance. Arch Argent Pediatr 2017;115(2):148-154.

\section{INTRODUCTION}

Lactose intolerance (LI) is a condition where there is a deficiency of the intestinal lactase enzyme. Such deficiency makes the lactose reaching the colon to be fermented by bacteria that synthesize short-chain fatty acids (propionic and butyric acids), hydrogen ions, and methane, which are responsible for LI signs and symptoms, ${ }^{1}$ including abdominal distension $(79 \%)$, abdominal pain $(47 \%)$, diarrhea $(45 \%)$, nausea and vomiting $(10 \%)$, and flatulence. ${ }^{2}$ Patients with LI and methaneproducing intestinal flora may also have constipation. ${ }^{3}$

The prevalence of LI is affected by different variables such as age and race. ${ }^{4}$ J. N. Keith et al. reported an LI prevalence of approximately $20 \%, 10 \%$, and $8 \%$ among African Americans, Hispanic Americans, and European Americans, respectively. ${ }^{5}$ Data from a child population of Indonesia show a prevalence of lactose malabsorption of $21.3 \%$ in children aged $3-5,57.8 \%$ in children aged $6-11$, and $73 \%$ in children aged 12-14; whereas in the Mexican population, the prevalence of LI has been reported to be $41.7 \%, 46.4 \%$, and $40.5 \%$ in preschool children (3-5 years old), school children (6-12 years old), and adolescents (13-17 years old), respectively, ${ }^{3}$ evidencing age-related variations.

There are different, highly sensitive and specific diagnostic methods; however, most are expensive, invasive, or poorly accessible for the general population. For example, the lactose tolerance test involves the oral 
administration of lactose followed by glycemia determinations. This test has a sensitivity of $94 \%$ and a specificity of $96 \%$.

Another method is the determination of enzymatic activities in jejunal biopsy, which offers a sensitivity of $95 \%$ and a specificity of $90 \%{ }^{7}$ Genotyping of polymorphisms has a sensitivity of $68.5 \%$ and a specificity of $92.5 \% .{ }^{8}$ Recently, a new urine gaxilose test has been introduced, which consists in administering oral gaxilose followed by the determination of the monosaccharide (xylose) in urine. ${ }^{9,10}$ Its sensitivity is $90 \%$, and its specificity, $92.8 \%$. Finally, the hydrogen breath test, which is considered the gold standard and is the most commonly used test, has a sensitivity of $90-100 \%$ and a specificity of $70-100 \% .^{11,12}$

In patients with lactose intolerance, an increase in waist circumference (WC) secondary to lactose intake can be measured with a tape measure and is an accessible, inexpensive, and noninvasive method. Abdominal distension has been reported in the literature as a manifestation of LI in up to $79 \%$ of patients, ${ }^{2}$ however, no studies have been conducted including quantitative measures to establish a cut-off point for the diagnosis of LI, therefore, establishing a reference value to determine the presence or absence of gastrointestinal disorders, such as LI, is highly relevant. The impact of obesity on abdominal distension is still unknown, so it will be included in the analysis.

\section{OBJECTIVES}

The primary objective of this study was to assess the usefulness of the increase in WC during the hydrogen breath test as a predictor of LI. The secondary objective was to analyze the impact of body mass index (BMI), waist circumference measurement, and age on abdominal distension of patients with lactose intolerance.

\section{POPULATION AND METHODS}

This was an analytical, observational, crosssectional, comparative study. The sample included 3-15 year-old patients referred to Hospital Universitario Dr. José Eleuterio González in Monterrey, Nuevo León, Mexico, in the period between October 2014 and October 2015 for their study due to gastrointestinal symptoms, including abdominal pain, abdominal distension, constipation, and flatulence. The sample size was estimated based on the formula for a diagnostic test with a bilateral $95 \%$ confidence, a bilateral
$Z$ value of 1.96 , a $90 \%$ expected sensitivity, and a 0.10 precision for sensitivity, which required a minimum of 138 patients. Inclusion criteria were as follows: previously healthy patients, no history of antibiotic therapy in the 2 weeks prior to the test, and fasting for 8 hours. Patients with pulmonary or neurological disease were excluded.

The sample was classified as per the Z-score classification by the World Health Organization (WHO) into underweight, normal weight, overweight, and obesity. ${ }^{13}$ Patients were analyzed to establish the impact of nutritional status on abdominal distension.

Parents' informed consent and patients' assent were obtained prior to study initiation. The study was approved by the Ethics Committee of Hospital Universitario Dr. José Eleuterio González.

\section{Hydrogen breath test}

Exhaled hydrogen was determined using the Gastro+ Gastrolyzer ${ }^{\circledR}$ equipment (Bedfont Scientific Ltd., Kent, England) as per the manufacturer's protocol. Medical staff instructed patients on how to correctly exhale into the equipment mouthpiece; no patient showed difficulties to follow directions. The youngest patient was 56 months old and provided an adequate sample in the first attempt. Before starting the test, patients were requested to use the toilet to avoid any interruptions during the study due to the urge to urinate. The baseline hydrogen level was obtained before the administration of lactose, estimated at $1 \mathrm{~g}$ per $\mathrm{kg}$ of body weight diluted at $10 \%$ in water at room temperature. ${ }^{14}$ Patients remained resting to prevent any variations in hydrogen ion secretion. The concentration of exhaled hydrogen ions was expressed as parts per million (ppm) at baseline and at 30,60, 90, 120, 150, and 180 minutes. ${ }^{15,16}$ Patients remained fasting during the 3 hours of the test, and their only calorie intake was the lactose administered at test initiation. Patients had lunch once the test ended and were, therefore, able to complete all determinations in one visit.

The sample was divided into 2 groups: patients with lactose intolerance, i.e., those who showed an increase of $20 \mathrm{ppm}$ in exhaled hydrogen between the baseline value and any of the 6 determinations made during the test, and patients without lactose intolerance, i.e., those who did not show such increase. ${ }^{17,18}$ 


\section{Waist circumference measurement}

A trained staff measured the WC using a non-extensible tape measure (Lufkin Executive Thinline 2m/6ft W606Me; Apex Tool Group, LLC, Sparks, MD) with a $0.1 \mathrm{~cm}$ precision. These measurements were done at the same time as the hydrogen breath test, one at baseline and then every 30 minutes over 3 hours. Patients were asked to stand with their arms raised up and their abdomen uncovered, and the measurement was taken at the end of a normal exhalation at the midline between the last rib and the iliac crest, according to the international standardized technique. ${ }^{19}$ Each measurement was taken 3 times and the average was obtained. WC measurements were taken by staff members who were blinded to the hydrogen breath test.

\section{Statistical analysis}

The analysis was done using the IBM SPSS Statistics software package, version 20 (IBM Corp., Armonk, NY). For descriptive statistics purposes, quantitative outcome measures with a normal distribution were expressed as mean and standard deviation. The $\chi^{2}$ test was used for the bivariate analysis of categorical outcome measures, and Student's t test was used for independent samples. The analysis of variance (ANOVA) or the Kruskal Wallis H test were used to compare two or more groups. The Friedman test was used to compare the course of each group based on hydrogen ion determinations and WC measurements. The Receiver Operating Characteristic (ROC) curve was used to establish the cut-off value for the increase in WC. The odds ratio (OR) was used to estimate the ratio of the association between positive/negative hydrogen breath tests and the increase or not in WC at 120 minutes $(95 \%$ confidence interval [CI]). A value of $p<0.05$ was considered statistically significant.

\section{RESULTS}

A total of 160 patients were assessed; 22 were excluded (Figure 1). One hundred and thirty-eight patients were included and completed the study; of these, $103(74.6 \%)$ were included in the group without LI, and 35 (25.4\%), in the group with LI based on their result on the hydrogen breath test (Figure 1). Demographic characteristics are described in Table 1.

\section{Increase in the waist circumference measurement of patients with lactose intolerance versus those without lactose intolerance}

Patients with lactose intolerance showed the greatest increase in hydrogen level at 120 minutes (Figure 2), which was consistent with the peak increase in WC, also observed at 120 minutes (Figure 3).

In relation to the increase in WC, a cut-off value was established at $0.85 \mathrm{~cm}$ from baseline WC to WC at 120 minutes, and the test showed a sensitivity of $88 \%$ and a specificity of $85 \%$, with an area under the ROC curve of 0.922 , and a $p \leq 0.001$ (Figure 4). The positive and negative predictive values were $64 \%$ and $93 \%$, respectively. The OR was 42.14 , with a $95 \%$ CI of $13.08-135.75$. The increase in WC ranged between $0.0 \mathrm{~cm}$ and $3 \mathrm{~cm}$.

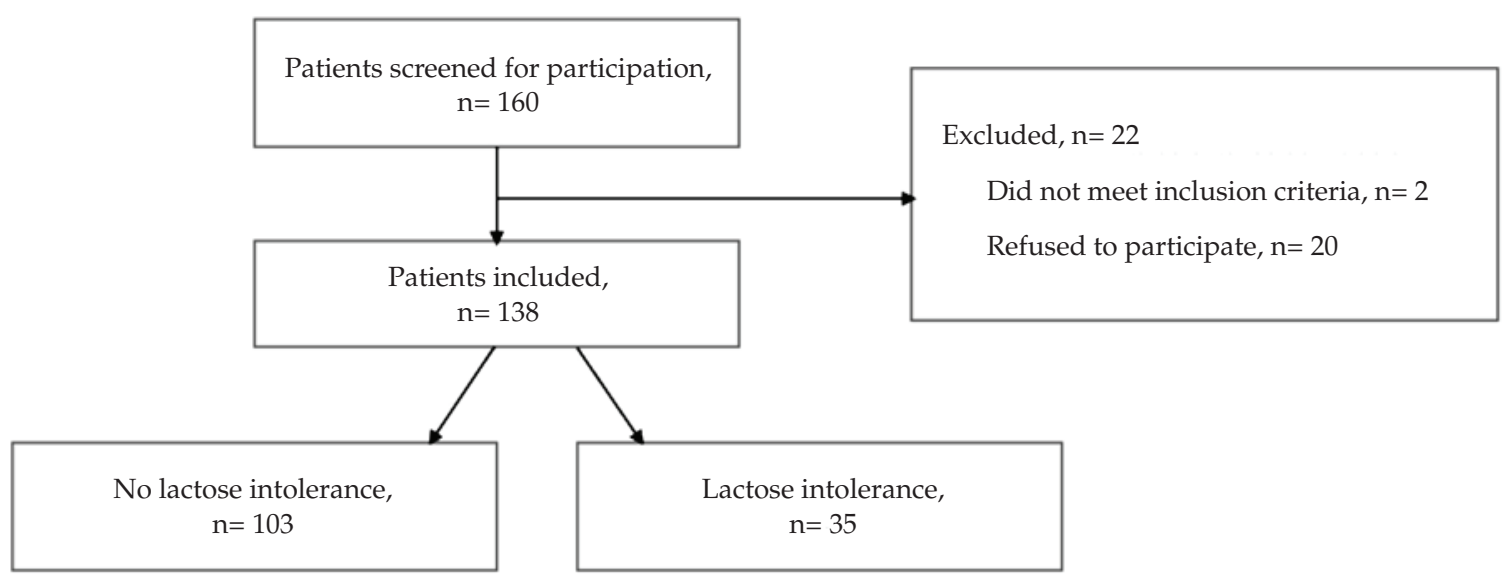


In the analysis by age group, cut-off points were different from those observed in the general population, which showed statistically significant differences. Cut-off points are described in Table 2.

\section{Prevalence of lactose intolerance by age group}

Children were classified into 3 groups to establish LI prevalence based on age groups: in the 3-5-year-old group, it was 9.3\% (5); in the 6-12-year-old group, $37.3 \%$ (25); and in the $>12$-year-old group, $29.4 \%$ (5). A statistically significant difference was observed among groups $(p<0.002)$.
The mean age of patients without LI was $7.11 \pm 3.43$ years old whereas in the group with LI it was $9.03 \pm 3.12$ years old, with a statistically significant difference $(p<0.004)$ and an age range between 4.8 and 15.3 years old.

\section{Lactose intolerance and waist circumference}

It is unknown whether the panniculus adiposus influences abdominal distension. To analyze this outcome measure, 3 groups were studied based on their WC: in the group with a WC of $40-60 \mathrm{~cm}, 54.3 \%$ (19) had LI; in the group

TABLE 1. Demographic characteristics of both study groups

\begin{tabular}{lcccc}
\hline & $\mathbf{N}(\mathbf{1 3 8})$ & Without lactose intolerance $(\mathbf{n}=\mathbf{1 0 3})$ & Lactose intolerance $(\mathbf{n}=\mathbf{3 5})$ & $p$ \\
\hline Age $(\mathrm{a})$ & $7.59 \pm 3.44$ & $7.11 \pm 3.43$ & $9.03 \pm 3.12$ & 0.004 \\
Male, $\mathrm{n}(\%)$ & $61(44.2)$ & $42(40.8)$ & $19(54.3)$ & $\mathrm{NS}$ \\
Female, $\mathrm{n}(\%)$ & $77(55.7)$ & $61(59.2)$ & $16(45.7)$ & NS \\
Weight $(\mathrm{kg})$ & $31.02 \pm 18.67$ & $29.92 \pm 19.22$ & $34.26 \pm 16.79$ & $\mathrm{NS}$ \\
Height $(\mathrm{m})$ & $1.24 \pm 0.20$ & $1.22 \pm 0.20$ & $1.29 \pm 0.19$ & $\mathrm{NS}$ \\
BMI $\left(\mathrm{kg} / \mathrm{m}^{2}\right)$ & $18.40 \pm 5.08$ & $18.14 \pm 5.22$ & $19.18 \pm 4.61$ & $\mathrm{NS}$ \\
\hline
\end{tabular}

Data are expressed as mean \pm standard deviation (SD).

NS: not significant; BMI: body mass index.

TABLE 2. Results of the Receiver Operating Characteristic curve analysis in the total population and by age group

\begin{tabular}{|c|c|c|c|c|c|c|c|}
\hline $\begin{array}{l}\text { Age } \\
\text { group }\end{array}$ & $\mathbf{n}$ & $\begin{array}{c}\text { Increase } \\
\text { in WC }(\mathrm{cm})\end{array}$ & $\begin{array}{c}\text { Time } \\
\text { (minutes) }\end{array}$ & $\begin{array}{c}\text { Sensitivity } \\
(\%)\end{array}$ & $\begin{array}{c}\text { Specificity } \\
(\%)\end{array}$ & $\begin{array}{c}\text { Area under } \\
\text { the ROC curve }\end{array}$ & $p$ \\
\hline Total population & 138 & 0.85 & 120 & 88 & 85 & 0.922 & $<0.001$ \\
\hline $3-5$ years old & 81 & 1.25 & 180 & 80 & 100 & 0.903 & 0.001 \\
\hline $6-12$ years old & 33 & 0.85 & 120 & 88 & 88 & 0.912 & $<0.001$ \\
\hline$>12$ years old & 24 & 0.95 & 60 & 100 & 75 & 0.933 & 0.006 \\
\hline
\end{tabular}

WC: waist circumference; cm: centimeters; ROC: Receiver Operating Characteristic.

FIGURE 2. Mean concentrations of exhaled hydrogen ions (parts per million) in the group with lactose intolerance $(n=35)$ and in the group without lactose intolerance $(n=103)$

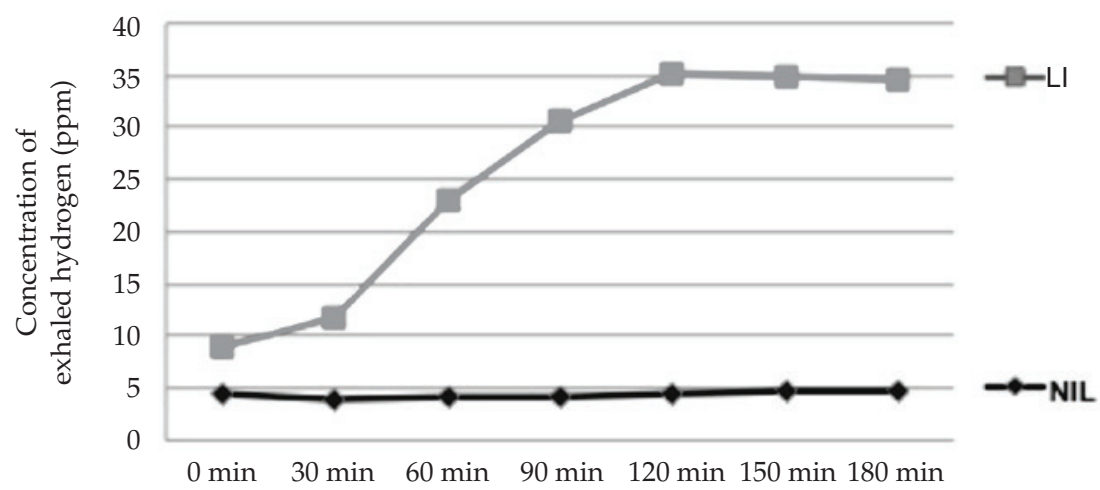

LI: lactose intolerance; ppm: parts per million; NIL: without lactose intolerance. 
with a WC of $60.01-80 \mathrm{~cm}, 34.3 \%(12)$ had LI; and in the group with WC above $80.01 \mathrm{~cm}, 11.4 \%$ (4) had LI. No statistically significant differences were observed among groups ( $p=$ not significant).

\section{Lactose intolerance and nutritional status}

Four groups were analyzed based on their Z-score to assess the impact that overweight and obesity may have on abdominal distension in the

FIGURE 3. Mean increase in waist circumference $(\mathrm{cm})$ during the hydrogen breath test in the group with lactose intolerance $(n=35)$ and in the group without lactose intolerance $(n=103)$

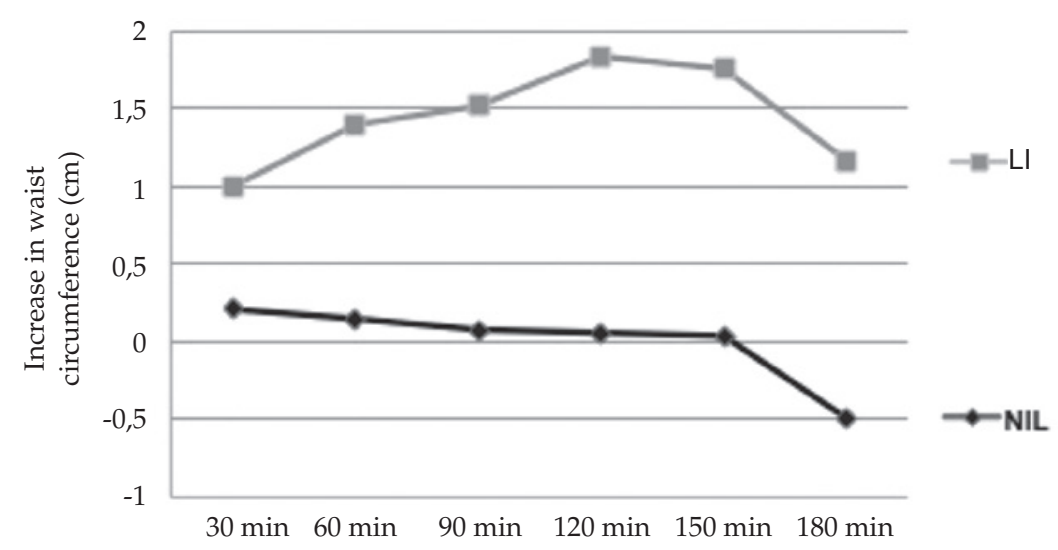

LI: lactose intolerance; ppm: parts per million; NIL: without lactose intolerance.

FIGURE 4. Receiver Operating Characteristic curve for the determination of cut-off points for the increase in waist circumference

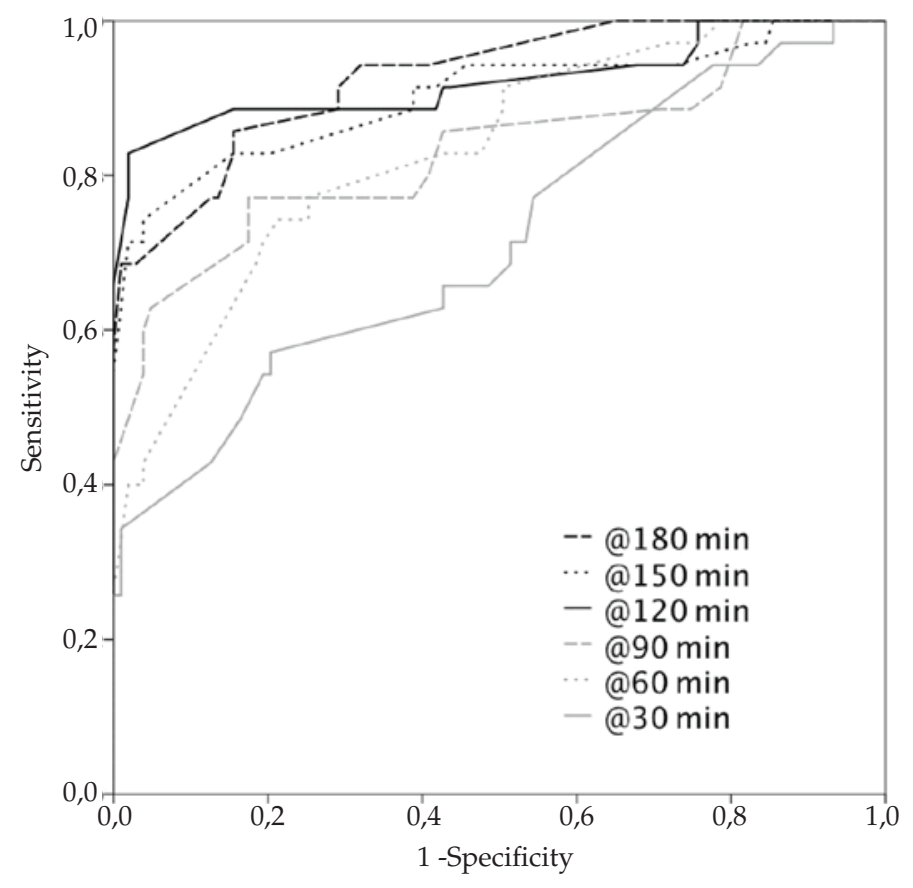

An increase of $0.85 \mathrm{~cm}$ at 120 minutes showed a sensitivity of $88 \%$ and a specificity of $85 \%$. Min: minutes. 
studied population: $2.85 \%$ (1) of patients were underweight, $60 \%$ (21) had a normal weight, $22.8 \%$ (8) were overweight, and $14.28 \%$ (5) were obese. No significant differences were found $(p=$ not significant).

\section{DISCUSSION}

Making a timely diagnosis of LI is greatly important because this is a common condition in pediatrics and its wrong diagnosis will pose nutritional and psychological consequences..$^{20,21}$ For this reason, there are, at present, several diagnostic methods that offer an adequate sensitivity and specificity. However, these methods may be costly, poorly accessible, or invasive, limiting their use in pediatrics. ${ }^{22,23}$ Hence the importance of having a clinical indicator for the diagnosis of LI in a simple, inexpensive, and accessible manner.

In our study, the LI prevalence was higher $(37.3 \%)$ in the group of patients aged 6-12 years; but such behavior was not observed in the child population of Indonesia, where the highest prevalence $(73 \%)$ was observed at $12-14$ years old, ${ }^{24}$ or in the child population of China, where the highest prevalence $(33,1 \%)$ was observed in the 7-8-year-old group. ${ }^{6,24}$ To account for such differences, it has been previously described that lactase activity varies among geographic locations and populations around the world. Some studies have suggested that the heterozygous genetic polymorphism may be a determining factor for an individual's tolerance or intolerance to lactose. Family studies have even suggested that $\mathrm{LI}$ is inherited as an autosomal recessive trait. ${ }^{25}$ Meanwhile, in a child population of Mexico, the higher prevalence was observed in the group aged 6-12 years, in $46.4 \%$ (4) of participants; i.e., the same behavior as in our sample. ${ }^{3}$

The mean age in the group of patients with LI was older compared to the group without LI; such difference was statistically significant. This finding is similar to what has been reported in the literature, where a clear increase has been observed in LI prevalence as patients grow old. ${ }^{26}$

In this study, an increase of $0.85 \mathrm{~cm}$ in WC during the hydrogen breath test was found to be sensitive and specific for the diagnosis of LI, but there are no previous data to compare these results.

In our study population, abdominal distension was a more common sign in patients with LI compared to those without LI; the latter also showed an increase in $\mathrm{WC}$, probably secondary to the volume of administered fluids.
In Mexico, the prevalence of overweight and obesity in children younger than 5 years is $9.7 \%$. The combined prevalence of these disorders is $34.4 \%$ in the school age population (5-11 years old), and 35\% among adolescents (12-19 years old). ${ }^{27}$ Obese patients have a thicker panniculus adiposus, so the potential impact it may have on distension was analyzed. It was observed that BMI and/or WC did not have a significant impact on the size of abdominal distension when comparing patients with and without LI.

The population was divided into 3 age groups (3-5 years, 6-12 years, and older than 12 years) to determine if there was a difference in the increase in WC related to age. Such analysis showed that age did not have a significant impact on the size of the increase in WC; however, a statistically significant difference was observed in relation to the moment at which the most effective cutoff points for increase in WC were found in each group. The highest increase in WC was observed late (180 minutes) in the patients from the 3-5-year-old group.

On the contrary, patients older than 12 years old showed an early peak (60 minutes). Similarly to what has been observed in the general population, the most effective cut-off point in the 6-12-year-old group also occurred at 120 minutes.

Such behavior describing an earlier occurrence of the maximum increase in WC as age increases (3-5 years old: 180 minutes; 6-12 years old: 120 minutes; and < 12 years old: 60 minutes) suggests that the cause may lie in already known factors, such as differences in the amount of bacteria in the gastrointestinal tract according to age ${ }^{28}$ and the reduction in lactase activity, also related to age. ${ }^{6}$

A weakness of this study is that patients whose flora did not produce hydrogen ions were not included, so further research is needed including the determination of methane. In addition, the sample size is small, especially once it is subdivided into age groups. However, it is worth mentioning that this study focused on assessing the differences in the increase in WC during the hydrogen breath test in pediatric patients with LI, and it is the only study that has assessed the effectiveness of using this sign as a clinical predictor.

\section{CONCLUSION}

A $0.85 \mathrm{~cm}$ increase in WC from baseline to 120 min in the hydrogen breath test is an accessible, non-invasive sign that may be implemented as a clinical predictor in children with suspected LI, 
whose nutritional status and waist circumference do not modify the usefulness of the increase in WC and whose age only affects the time of onset.

\section{Acknowledgments}

The authors would like to thank M. C. Neri Alejandro Álvarez-Villalobos, M.D., for his help with the statistical analysis, and Sergio Lozano, M.D., for his help with the translation, and also to our patients and their parents for agreeing to participate in the study.

\section{REFERENCES}

1. He T, Venema K, Priebe MG, Welling GW, et al. The role of colonic metabolism in lactose intolerance. Eur J Clin Invest 2008;38(8):541-7.

2. Zahid A, Shaukat A, Mahmood KT. Lactose Intolerance. J Biomed Sci and Res 2010;2(4):290-4.

3. Moran S, Mina A, Duque X, Anaya S, et al. Prevalence of Lactose Malabsorption in Mexican Children: Importance of Measuring Methane in Expired Air. Arch Med Res 2013;44(4):291-5.

4. Wilt TJ, Shaukat A, Shamliyan T, Taylor BC, et al. Lactose intolerance and health. Rockville, MD: Agency for Healthcare Research and Quality, 2010. [Accessed on: October $\left.7^{\text {th }}, 2016\right]$. Available at: http://www.ahrq. gov/sites/default/files/wysiwyg/research/findings / evidence-based- reports/lactint-evidence-report.pdf.

5. Keith JN, Nicholls J, Reed A, Kafer K, et al. The Prevalence of Self-reported Lactose Intolerance and the Consumption of Dairy Foods Among African American Adults Are Less Than Expected. J Natl Med Assoc 2011;103(1):36-45.

6. Hegar B, Widodo A. Lactose intolerance in Indonesian children. Asia Pac J Clin Nutr 2015;24(Suppl 1):S31-40.

7. Mattar R, de Campos Mazo DF, Carrilho FJ. Lactose intolerance: diagnosis, genetic, and clinical factors. Clin Exp Gastroenterol 2012;5:113-21.

8. Nilsson TK, Olsson LA. Simultaneous genotyping of the three lactose tolerance-linked polymorphisms LCT -13907 C $>$ G, LCT -13910 C $>$ T and LCT -13915 T $>$ G with Pyrosequencing technology. Clin Chem Lab Med 2008;46(1):80-4.

9. Hermida C, Guerra P, Martínez-Costa OH, Sánchez V, et al. Phase I and phase IB clinical trials for the noninvasive evaluation of intestinal lactase with 4-galactosylxylose (gaxilose). J Clin Gastroenterol 2013;47(6):501-8.

10. Aragón JJ, Hermida C, Martínez-Costa $\mathrm{OH}$, Sánchez $\mathrm{V}$, et al. Noninvasive diagnosis of hypolactasia with 4-Galactosylxylose (Gaxilose): a multicentre, open-label, phase IIB-III nonrandomized trial. J Clin Gastroenterol 2014;48(1):29-36.

11. Gasbarrini A, Corazza GR, Gasbarrini G, Montalto M, et al. Methodology and indications of H2-breath testing in gastrointestinal diseases: the Rome Consensus Conference. Aliment Pharmacol Ther 2009;29(Suppl 1):1-49.
12. Hovde O, Farup PG. A comparison of diagnostic tests for lactose malabsorption-which one is the best? $B M C$ Gastroenterol 2009;9:82.

13. WHO Multicentre Growth Reference Study Group. WHO Child Growth Standards: Length/height-for-age, weightfor-age, weight-for-length, weight-for-height and body mass index-for-age: Methods and development. Geneva: World Health Organization, 2006. [Accessed on: October $\left.7^{\text {th }}, 2016\right]$. Available at: apps.who.int/iris/bitstream/ 10665/43413/1/924154693X_eng.pdf.

14. Heyman MB, Committee on Nutrition. Lactose intolerance in Infants, Children, and Adolescents. Pediatrics 2006;118(3):1279-86.

15. Kerber M, Oberkanins C, Kriegshäuser G, Kollerits B, et al. Hydrogen breath testing versus LCT genotyping for the diagnosis of lactose intolerance: A matter of age? Clin Chim Acta 2007;383(1-2):91-6.

16. Carter SL, Attel S. The diagnosis and management of patients with lactose-intolerance. Nurse Pract 2013;38(7):238.

17. Simrén M, Stotzer PO. Use and abuse of hydrogen breath tests. Gut 2006;55(3):297-303.

18. Ghoshal UC. How to Interpret Hydrogen Breath Tests. J Neurogastroenterol Motil 2011;17(3):312-7.

19. WHO. Chronic diseases and health promotion. STEPwise approach to surveillance (STEPS). [Accessed on: October $\left.7^{\text {th }}, 2016\right]$. Available at: http:/ / www.who.int/chp/steps / en/.

20. Vilotte JL. Lowering the milk lactose content in vivo: potential interests, strategies and physiological consequences. Reprod Nutr Dev 2002;42(2):127-32.

21. Buchowski MS, Semenya J, Johnson AO. Dietary calcium intake in lactose maldigesting intolerant and tolerant African-American women. J Am Coll Nutr 2002;21(1):47-54.

22. Savaiano DA, Boushey CJ, McCabe GP. Lactose intolerance symptoms assessed by meta-analysis: a grain of truth that leads to exaggeration. J Nutr 2006;136(4):1107-13.

23. Kenny P. Dolor abdominal funcional en niños. Arch Argent Pediatr 1998;96(5):334-43.

24. Barling PM. Lactose tolerance and intolerance in Malaysians. IeJSME 2012;6(Suppl 1):S12-23.

25. Perino A, Cabras S, Obinu D, Cavalli Sforza L. Lactose intolerance: a non-allergic disorder often managed by allergologists. Eur Ann Allergy Clin Immunol 2009;41(1):316.

26. Schirru E, Corona V, Usai-Satta P, Scarpa M, et al. Decline of lactase activity and c/t-13910 variant in Sardinian childhood. J Pediatr Gastroenterol Nutr 2007;45(4):503-6.

27. Gutiérrez JP, Rivera-Dommarco J, Shamah-Levy T, Villalpando-HernándezS, etal. Encuesta Nacional deSalud y Nutrición 2012. Resultados Nacionales. Cuernavaca: Instituto Nacional de Salud Pública, 2012. [Accessed on: October $\left.7^{\text {th }}, 2016\right]$. Available at: http:/ / ensanut.insp.mx/ informes/ENSANUT2012ResultadosNacionales.pdf.

28. Merchant HA, Liu F, Orlu GM, Basit AW. Age-mediated changes in the gastrointestinal tract. Int J Pharm 2016. Oct 30;512(2):382-395. 